\title{
Meningkatkan Aktivitas dan Hasil Belajar Laundry melalui Pembelajaran Berbasis Project Based Learning (PJBL)
}

\author{
Nyoman Aris Suparni ${ }^{1 *}$ \\ ${ }^{1}$ SMK Negeri 3 Denpasar, Denpasar, Indonesia
}

\section{A R T I C L E I N F O}

Article history:

Received 19 February 2021

Received in revised form

25 March 2021

Available online 11 May 2021

Kata Kunci:

Project Based Learning

(Pjbl), Aktivitas, Hasil

Belajar.

Keywords:

Project Based Learning (Pjbl), Activity, Learning Outcomes
Accepted 10 April 2021

\begin{abstract}
A B S T R A K
Penelitian ini bertujuan untuk menganalisis aktivitas dan hasil belajar laundry melalui pembelajaran berbasis $P j B L$ pada siswa kelas XII. Penelitian ini termasuk jenis penelitian tindakan kelas (PTK). Subyek penelitian ini adalah aktivitas dan hasil belajar laundry siswa kelas XII dengan melibatkan 35 orang siswa. Metode pengumpulan data yang digunakan adalah pemberian lembar observasi dan penugasa/proyek yang diberikan kepada siswa untuk memperoleh data mengenai aktivitas dan hasil belajar siswa. Data yang diperoleh dianalisis dengan teknik analisis data statistik kuantitatif. Hasil penelitian ini menunjukkan bahwa aktivitas belajar siswa ada peningkatan rata-rata kategori aktivitas siswa meningkat pada kategori sangat aktif dan hasil belajar siswa pada pelajaran laundry melalui pembelajaran berbasis $P j B L$ pada siklus 1 menunjukan bahwa ketuntasan belajar siswa sebesar $42,85 \%$, daya serap $73,86 \%$. Pada siklus 2 menunjukan bahwa ketuntasan belajar siswa sebesar $71,43 \%$, daya serap $79,29 \%$ dan pada siklus 3 menunjukan bahwa ketuntasan belajar siswa sebesar $100 \%$, daya serap $89,14 \%$. Dari hasil penelitian tersebut dapat disimpulkan bahwa dengan
\end{abstract} penerapan pembelajaran berbasis PjBL dapat meningkatkan aktivitas dan hasil belajar siswa pada mata pelajaran laundry. Implikasi penelitian ini adalah dengan penerapan model pembelajaran PjBL akan membuat suasana pembelajaran yang aktif, kreatif, efektif dan menyenangkan, sehingga akan berdampak pada pembelajaran yang lebih bermakna bagi siswa.

\section{A B S T R A K}

This research aims to analyze the activities and results of learning laundry through PjBL-based learning for class XII students. This research is a type of classroom action research (PTK). The subjects of this study were the activities and learning outcomes of class XII student laundry involving 35 students. The data collection method used was the provision of observation sheets and assignments / projects that were given to students to obtain data about student activities and learning outcomes. The data obtained were analyzed using quantitative statistical data analysis techniques. The results of this study indicate that student learning activities have an increase in the average category of student activity increases in the very active category and student learning outcomes in laundry lessons through PjBL-based learning in cycle 1 indicate that student learning completeness is $42.85 \%$, absorption $7386 \%$. In cycle 2 shows that student learning completeness is $71.43 \%$, absorption ability is $79.29 \%$ and in cycle 3 shows that student learning completeness is $100 \%$, absorption ability $89.14 \%$. From the results of these studies it can be concluded that the application of PjBL-based learning can improve student activity and learning outcomes in laundry subjects. The implication of this research is that the application of the PjBL learning model will create an active, creative, effective and enjoyable learning atmosphere, so that it will have an impact on more meaningful learning for students.

Copyright (@) Universitas Pendidikan Ganesha. All rights reserved 


\section{Pendahuluan}

Mencerdaskan kehidupan bangsa dapat diwujudkan melalui pendidikan, sistem pendidikan yang baik akan melahirkan generasi bangsa yang cerdas dan baik pula. Generasi bangsa yang cerdas ialah modal awal bagi suatu bangsa dalam melakukan pembangunan ke arah yang lebih baik dalam usaha mencapai pembangunan nasional (Amelia \& Saputra, 2017; Kurniaman \& Noviana, 2017; Nuryana \& Sahrir, 2020). Pembangunan yang dilakukan oleh suatu bangsa menandakan bahwa bangsa tersebut merupakan bangsa yang bermartabat karena selalu melakukan peningkatan kualitas dan beradaptasi dengan peradaban zaman. Dari pernyataan tersebut tersirat pesan bahwa pendidikan perlu mendapatkan perhatian yang serius. Pendidikan merupakan salah satu bidang yang mempunyai peranan besar dalam pembangunan di suatu negera selain bidang ekonomi, politik, keamanan, dan sebagainya. Maju mundurnya bangsa banyak ditentukan oleh maju mundurnya pendidikan, oleh karena itu pendidikan harus dilaksanakan sebaikbaiknya agar memperoleh hasil yang maksimal (Ardianingsih et al., 2017; Divayana et al., 2016; Krissandi \& Rusmawan, 2015). Pendidikan dan pengajaran adalah suatu proses yang sadar tujuan. Tujuan dapat diartikan sebagai suatu usaha untuk memberikan rumusan hasil yang diharapkan siswa setelah melaksanakan pengalaman belajar. Tercapai tidaknya tujuan pengajaran salah satunya adalah terlihat dari prestasi belajar yang diraih siswa, dengan prestasi yang tinggi, para siswa mempunyai indikasi berpengetahuan yang baik (Kurniaman \& Noviana, 2017; Kurniasari, 2017; Raditya \& Iskandar, 2020).

Pembelajaran Tantangan perkembangan teknologi disruptif pada dunia industri, dunia usaha dan dunia kerja (DIDUKA) sekarang ini membawa konsekuensi logis terhadap tuntutan akan tenaga terampil lulusan Sekolah Menengah Kejuruan (SMK). Pada saat seperti ini peran industri sangat strategis karena industri sebagai pengguna tenaga kerja yang dihasilkan oleh penyedia jasa salah satunya adalah SMK. Memperhatikan dinamika persyaratan kebutuhan ketenagarjaan di dunia dunia industri, dunia usaha dan dunia kerja (DIDUKA) dan perkembangan ilmu dan teknologi (IPTEK) yang relatif cepat, SMK dituntut antisipatif untuk menyiapkan tenaga kerja yang mampu bersaing di masa datang. Langkah strategis yang dapat dilakukan untuk memenuhi tuntutan tersedianya tenaga kerja berkualitas agar out come tamatan SMK dapat diterima di industri adalah dengan program kemitraan dan keselarasan (Link and Match) (Hasanah et al., 2018; Mutakinati \& Anwari, 2018; Pratiwi \& Setyaningtyas, 2020).

Berdasarkan hasil observasi di SMKN 3 Denpasar, berbicara SMK tidak terlepas dari struktur kurikulum yang harus dipelajari dalam kurun waktu 3 tahun. Tujuan pokok dari kurikulum tersebut yaitu membekali siswa agar memiliki kopetensi kerja sesuai Standard Kompetensi Kerja Nasional Indonesia (SKKNI). Kompetensi yang diberikan kepada siswa SMK lebih menekankan pada pengetahuan, keterampilan dan sikap dengan persentase $70 \%$ untuk praktek dan $30 \%$ untuk teori. Kenyataannya saat ini dimasa pandemi covid-19 sedang merebak, menyebabkan kegiatan praktik untuk mata pelajaran laundry tidak dapat dilakukan secara penuh sesuai dengan tuntutan kurikulum. Kegiatan pembelajaran yang seharusnya banyak menyentuh industri melalui kegiatan praktik akhirnya terganti dengan pembelajaran jarak jauh atau pembelajaran dalam jaringan (daring), keadaan ini menyebabkan siswa cenderung menerima informasi dari guru yang mengakibatkan siswa tidak aktif. Disamping itu Siswa tidak bisa dikontrol secara penuh karena banyak yang tidak mengikuti pembelajaran secara daring dengan alasan sinyal kurang bagus, kuota habis dan alasan yang lainnya. Situasi ini berdampak pada rendahnya aktivitas siswa. Kegiatan praktik tidak dapat dilakukan secara optimal dan terkesan seadanya saja tanpa konsep, sehingga hasil belajar yang dicapai kurang optimal. Dari dampak tersebut menyebabkan dampak lebih lanjut yaitu rendahnya hasil belajar siswa di kelas tersebut. Hasil analisis skor perolehan nilai siswa kelas XII Perhotelan D untuk mata pelajaran Laundry adalah: dari 35 siswa hanya 11 orang $(30 \%)$ siswa yang dapat menuntaskan pelajaran dan 24 orang $(70 \%)$ siswa tidak dapat menuntaskan pelajaran dari ketuntasan minimal 80. Menghadapi permasalahn yang sangat kompleks tersebut maka perlu merubah paradigma pendidikan dengan menerapkan sistem pembelajaran yang sesuai dengan kondisi tersebut. Salah satu solusi yang dapat dilaksanakan adalah dengan menerapkan model pembelajaran Project Based Learning (PJBL).

Model pembelajaran Project Based Learning (PJBL) memberikan wahana belajar siswa sesuai dengan tantangan perkembangan teknologi, karena proyek yang dikerjakan siswa dibawa dari DIDUKA dengan spesifikasi dan standar industri, sehingga perkembangan teknologi di DIDUKA terakomodasi dalam pembelajaran di SMK (Kristiyanto, 2020; H. R. Kurniawan et al., 2018; Trimawati et al., 2020). Pelaksanaan pembelajaran PJBL siswa secara berkelompok, bekerjasama melaksanakan proses produksi meliputi dimensi melaksanakan tugas-tugas rutin (Task Skill), mengelola pekerjaan (Task Management Skill), memecahkan permasalahan dalam berproduksi (Continggency Managemant Skill) menjaga kelestarian lingkungan kerja (Roll Enviromant Managemant Skill) dan menggunakan teknologi sesuai 
perkembangan yang ada di DIDUKA (Transfer Skill) secara kontekstual di lini produksi serta continual improvement (Afifah et al., 2019; D. T. Kurniawan, 2017; Purwaningsih et al., 2020).

Secara keseluruhan aktivitas belajar siswa dikontrol oleh tim kolaborator (guru, orang tua siswa, industri) kebiasaan bekerja seperti itu akan membangun siswa berperilaku professional dan meningkatkan kompetensinya secara terus menerus sesuai tuntutan DIDUKA. Tentunya dalam prosesnya nanti tetap memperhatikan regulasi pemerintah, dengan menerapkan aturan pencegahan covid-19 dan kerjasama dengan industri. Dengan proses belajar yang berbasis project-based learning tersebut akan meningkatkan aktivitas belajar siswa hal ini akan berdampak pada pembelajaran yang lebih bermakna. Dikatakan demikian karena model PjBL memiliki kelibihan yaitu: (1) adanya keterlibatan siswa dalam menyusun dan membuat perencanaan proses pembelajaran; (2) adanya keterlibatan intelektual emosional siswa melalui dorongan dan semangat yang dimilikinya; (3) adanya keikutsertaan siswa secara aktif dan kreatif dalam menyelesaikan tugas proyek-nya agar pembelajaran menjadi pembelajaran yang aktif, kreatif, efektif dan menyenangkan (Faizah, 2015; Faizin et al., 2017; Sumarni et al., 2016).

Penelitian ini didukung oleh beberapa penelitian-penelitian sebelumnya yaitu, pertama penelitian yang dilakukan oleh (Pratiwi \& Setyaningtyas, 2020), yang mendapatkan hasil berupa penerapan model pembelajaran Problem Based Learning dan model pembelajaran Project Based Learning dapat mempengaruhi kemampuan berpikir kritis siswa. Kedua, penelitian yang dilakukan oleh (Tesi Muskania \& Wilujeng, 2017), yang mendapatkan hasil berupa pengembangan perangkat pembelajaran berbasis Project-Based Learning terbukti berpengaruh terhadap kemampuan berpikir kritis siswa. Ketiga penelitian yang dilakukan oleh (Cahyaningsih et al., 2020), yang mendapatkan hasil berupa model Project Based Learning berbantu multimedia power point dinyatakan efektif untuk meningkatkan hasil belajar IPA.

Penelitian ini bertujuan untuk menganalisis aktivitas dan hasil belajar laundry melalui pembelajaran berbasis Project Based Learning (PjBL) pada siswa kelas XII Perhotelan D SMKN 3 Denpasar Tahun Pelajaran 2020./2021.

\section{Metode}

Prosedur penelitian yang dilakukan adalah Penelitian Tindakan Kelas (Classroom action Research) yang terdiri dari 3 siklus. Tiap siklus dilaksanakan sesuai dengan strategi pengorganisasian pembelajaran dengan perubahan yang dicapai, dengan cara melihat hasil observasi, evaluasi tindakan, refleksi dan dilakukan identifikasi kekurangan tindakan siklus 1, evaluasi hasil siklus 1 dilanjutkan ke siklus 2 dengan berpatokan pada refleksi siklus 1 , demikian seterusnya sampai siklus 3 . Subyek penelitian ini adalah aktivitas dan hasil belajar laundry siswa kelas XII Perhotelan D SMKN 3 Denpasar dengan melibatkan 35 orang, terdiri dari siswa laki-laki sebanyak 20 orang dan siswa perempuan sebanyak 15 orang. Data yang dikumpulkan dalam penelitian ini meliputi data aktivitas belajar dan data hasil belajar siswa. Metode pengumpulan data yang digunakan adalah pemberian lembar observasi dan penugasa/proyek yang diberikan kepada siswa untuk memperoleh data mengenai aktivitas dan hasil belajar siswa. Instrumen yang digunakan adalah lembar observasi berupa check list dan penugasan/proyek pembutan proposal.

Data yang diperoleh dianalisis dengan teknik analisis data statistik kuantitatif. Pedoman yang digunakan untuk melakukan interpretasi terhadap data tentang hasil belajar secara klasikal adalah tercapainya Ketuntasan belajar $80 \%$, daya serap minimal $80 \%$, dan kriteria ketuntasan minimal (KKM) $80 \%$ serta ketuntasan materi $100 \%$. Secara keseluruhan penelitian ini dikatakan berhasil apabila aktivitas belajar siswa mengalami peningkatan baik itu dari tahap refleksi awal maupun dari siklus sebelumnya dan harus memenuhi kriteria yang ditetapkan. Aktivitas belajar siswa pada akhir siklus ke 3 minimal pada kriteria aktif. Hasil belajar yang diperoleh harus meningkat dari siklus sebelumnya dan pada akhir siklus tercapainya Ketuntasan belajar (KB) minimal 80\%, daya serap minimal (DS) $80 \%$, serta ketuntasan materi (KM) 100\%. Seluruh siswa dinyatakan kompeten dengan memperoleh KKM sebesar 80.

\section{Hasil dan Pembahasan}

Hasil Penelitian Siklus 1, data tentang aktivitas siswa dalam model pembelajaran berbais project based learning (PjBL) menunjukkan bahwa skor tertinggi yang dicapai siswa adalah 14 dari skor maksimal yang mungkin bisa dicapai yaitu 16. Data tentang hasil belajar siswa dalam pembelajaran berbasis project based learning (PjBL) pada siklus 1 menunjukkan bahwa skor tertinggi yang dicapai siswa adalah 80,00 dari skor maksimal yang mungkin bisa dicapai yaitu 100,00. Sedangkan skor terendah yang dicapai siswa adalah 60,00 dari skor minimal yang mungkin terjadi yaitu 0,00. Ketuntasan belajar siswa yang dicapai $42,85 \%$, Daya serap $73,86 \%$ dan ketuntasan materi $90,00 \%$. 
Hasil Penelitian Siklus 2, data tentang aktivitas siswa dalam pembelajaran berbasis project based learning (PjBL) menunjukkan bahwa skor tertinggi yang dicapai siswa adalah 15 dari skor maksimal yang mungkin bisa dicapai yaitu 16. Sedangkan skor terendah yang dicapai siswa adalah 10 dari skor minimal yang mungkin terjadi yaitu 4. Data tentang hasil belajar siswa dalam pembelajaran berbasis project based learning (PJBL) pada siklus 2 menunjukkan bahwa skor tertinggi yang dicapai siswa adalah 95,00 dari skor maksimal yang mungkin bisa dicapai yaitu 100,00. Sedangkan skor terendah yang dicapai siswa adalah 75,00 dari skor minimal yang mungkin terjadi yaitu 0,00. Ketuntasan belajar siswa yang dicapai 71,43\%, Daya serap 79,29\% dan ketuntasan materi $100 \%$.

Hasil Penelitian Siklus 3, data tentang aktivitas siswa dalam pembelajaran berbasis project based learning (PjBL) menunjukkan bahwa skor tertinggi yang dicapai siswa adalah 16 dari skor maksimal yang mungkin bisa dicapai yaitu 16. Sedangkan skor terendah yang dicapai siswa adalah 12 dari skor minimal yang mungkin terjadi yaitu 4. Data tentang hasil belajar siswa dalam pembelajaran berbasis project based learning (PjBL) pada siklus 3 menunjukkan bahwa skor tertinggi yang dicapai siswa adalah 100,00 dari skor maksimal yang mungkin bisa dicapai yaitu 100,00. Sedangkan skor terendah yang dicapai siswa adalah 80,00 dari skor minimal yang mungkin terjadi yaitu 0,00. Ketuntasan belajar siswa yang dicapai 100,00\%, Daya serap 89,14\% dan ketuntasan materi 100\%.

Perhitungan hasil belajar siswa pada siklus 1 yaitu ketuntasan belajar (KB) sebesar 42,85\% , daya serap (DS) 73,86\% dan ketuntasan materi (KM) 90,00\% dari kriteria ketuntasan minimal (KKM) 80. Dari 35 siswa subjek penelitian, 5 siswa $(11,11 \%)$ memperoleh skor 65 ; 9 siswa $(25,71 \%)$ memperoleh skor 70; 7 siswa $(20,00 \%)$ memperoleh skor $75 ; 13$ siswa $(37,14 \%)$ memperoleh skor $80 ; 1$ siswa $(2,86 \%)$ memperoleh skor 85. Untuk aktivitas siswa pada siklus 1 ada pada kategori cukup aktif .

Dari perolehan skor hasil belajar dan aktivitas siswa pada siklus 1 perlu perbaikan pada tindakan siklus 2. Pada tindakan siklus 1 masalah yang perlu diperbaiki yaitu pada aspek memberikan keleluasaan berkreasi dan berinovasi serta control yang lebih kuat dengan kegiatan : (1) guru merancang dan membuat kartu bimbingan untuk mengontrol kerja siswa (2) memberi alokasi waktu yang lebih banyak pada saat kegiatan praktik atau menyelesaikan project, (3) menyiapkan sumber belajar yang lebih komplek dan beragam serta pendukung belajar tidak dibatasi agar siswa dapat mengembangkan pengetahuan, keterampilan dan sikap selain di sekolah juga di usaha laundry di masyarakat.

Pada tindakan/siklus 2, guru mengubah cara pemberian tugas tetap melalui tugas kelompok yaitu mengambil cucian di usaha laundry masyarakat untuk dikerjakan di sekolah. Pada masa pandemi kegiatan tatap muka diijinkan oleh pemerintah daerah hanya untuk pelajaran praktik asalnya ada ijin dari orang tua siswa. Sumber belajar berasal dari buku referensi, perpustakaan, internet maupun lingkungan. Pada siklus 2 waktu, sumber belajar, dan pendukung belajar yang lain diperpanjang namun tetap ditentukan sehingga memungkinkan siswa dapat lebih mengembangkan pengetahuan yang dimilikinya dengan fasilitas belajar yang lebih kompleks dan beragam yang tersedia di sekolah maupun masyarakat, hal ini diduga kuat akan memberikan kesempatan kepada semua siswa untuk mengeluarkan potensi yang dimilikinya melalui tugas yang diberikan oleh guru sehingga siswa pada saat presentasi lebih banyak dapat menyiapkan diri sehingga berdampak pada meningkatnya kepercayaan diri pada saat bertanya maupun menjawab pertanyaan siswa lain. Hasil yang diperoleh pada siklus 2 adalah 71,43\% siswa tuntas dalam belajar (KB), daya serap (DS) 79,29\% dan ketuntasan materi (KM) $100 \%$ dari kriteria ketuntasan minimal (KKM) 80. Dari 35 siswa subjek penelitian, 3 siswa $(8,57 \%)$ memperoleh skor 70 ; 8 siswa (22,85\%) memperoleh skor 75; 19 siswa (54,28\%) memperoleh skor 80; 2 siswa (5,71\%) memperoleh skor 85 ; 3 siswa $(8,57 \%)$ memperoleh skor 90 . Untuk aktivitas belajar siswa ada peningkatan yaitu : ratarata kategori aktivitas siswa meningkat pada kategori aktif .

Dari perolehan skor hasil belajar dan aktivitas siswa pada siklus 2 sudah terjadi peningkatan dan tercapai target indikator penerimaan hipotesis tapi belum melibatkan industri khususnya hotel. Dengan demikian siswa perlu diberikan pengalaman tambahan untuk menyiapkan siswa dalam mengisi peluang kerja di hotel ketika menyelesaikan pendidikannya. Pada tindakan siklus 3 perlu merencanakan program pembelajaran yang lebih bebas tetapi tetap terarah dari segi waktu diperpanjang, sumber belajar diperluas, dan pendukung belajar diperkuat, memberikan keleluasaan dan pengalaman belajar siswa untuk belajar di dunia nyata dan riil . Rencana belajar akan dilakukan didua tempat yaitu di Sekolah dan di dunia usaha dan dunia kerja (DIDUKA) dalam penelitian ini dilakukan di Prama Sanur Beach Hotel Bali, yang sebelum pelaksanakaan diperkuat dengan kesepakatan bersama (MoU). Dengan memberikan siswa pengalaman belajar dari sumber belajar yang ada baik di Sekolah maupun IDUKA maka memungkinkan siswa dapat mengembangkan pengetahuan yang dimilikinya dengan fasilitas belajar yang lebih kompleks dan beragam, hal ini diduga kuat akan memberikan kesempatan kepada semua siswa untuk mengeluarkan potensi yang dimilikinya melalui tugas yang diberikan oleh guru sehingga siswa pada saat presentasi lebih banyak dapat mempersiapkan diri yang berdampak pada munculnya kepercayaan diri siswa karena sudah mendapat pengalaman belajar yang sangat kompleks yaitu di Hotel. Sementara dalam kegiatan 
praktek, siswa semakin antusias karena mendapat keleluasaan waktu dan kesempatan latihan lebih banyak.

Hasil yang diperoleh pada siklus 3 adalah 100\% siswa telah tuntas dalam belajar (KB), daya serap (DS) $89,14 \%$ dan ketuntasan materi (KM)100\% telah tuntas dalam pelajaran laundry. Dari 35 siswa subjek penelitian, 8 siswa (22,87\%) memperoleh skor $80 ; 7$ siswa $(20,00 \%)$ memperoleh skor $85 ; 10$ siswa (28,57\%) memperoleh skor 90; 6 siswa (17,14\%) memperoleh skor 95; 4 siswa $(11,42 \%)$ memperoleh skor 100 . Untuk aktivitas belajar siswa ada peningkatan yaitu : rata-rata kategori aktivitas siswa meningkat pada kategori sangat aktif.

Model pembelajaran Project Based Learning (PJBL) memberikan wahana belajar siswa sesuai dengan tantangan perkembangan teknologi, karena proyek yang dikerjakan siswa dibawa dari DIDUKA dengan spesifikasi dan standar industri, sehingga perkembangan teknologi di DIDUKA terakomodasi dalam pembelajaran di SMK (Kristiyanto, 2020; H. R. Kurniawan et al., 2018; Trimawati et al., 2020). Pelaksanaan pembelajaran PJBL siswa secara berkelompok, bekerjasama melaksanakan proses produksi meliputi dimensi melaksanakan tugas-tugas rutin (Task Skill), mengelola pekerjaan (Task Management Skill), memecahkan permasalahan dalam berproduksi (Continggency Managemant Skill) menjaga kelestarian lingkungan kerja (Roll Enviromant Managemant Skill) dan menggunakan teknologi sesuai perkembangan yang ada di DIDUKA (Transfer Skill) secara kontekstual di lini produksi serta continual improvement (Afifah et al., 2019; D. T. Kurniawan, 2017; Purwaningsih et al., 2020).

Secara keseluruhan aktivitas belajar siswa dikontrol oleh tim kolaborator (guru, orang tua siswa, industri) kebiasaan bekerja seperti itu akan membangun siswa berperilaku professional dan meningkatkan kompetensinya secara terus menerus sesuai tuntutan DIDUKA. Tentunya dalam prosesnya nanti tetap memperhatikan regulasi pemerintah, dengan menerapkan aturan pencegahan covid-19 dan kerjasama dengan industri. Dengan proses belajar yang berbasis project based learning tersebut akan meningkatkan aktivitas belajar siswa hal ini akan berdampak pada pembelajaran yang lebih bermakna. Dikatakan demikian karena model PjBL memiliki kelibihan yaitu: (1) adanya keterlibatan siswa dalam menyusun dan membuat perencanaan proses pembelajaran; (2) adanya keterlibatan intelektual emosional siswa melalui dorongan dan semangat yang dimilikinya; (3) adanya keikutsertaan siswa secara aktif dan kreatif dalam menyelesaikan tugas proyek-nya agar pembelajaran menjadi pembelajaran yang aktif, kreatif, efektif dan menyenangkan (Faizah, 2015; Faizin et al., 2017; Sumarni et al., 2016).

Penelitian ini didukung oleh beberapa penelitian-penelitian sebelumnya yaitu, pertama penelitian yang dilakukan oleh (Pratiwi \& Setyaningtyas, 2020), yang mendapatkan hasil berupa penerapan model pembelajaran Problem Based Learning dan model pembelajaran Project Based Learning dapat mempengaruhi kemampuan berpikir kritis siswa. Kedua, penelitian yang dilakukan oleh (Tesi Muskania \& Wilujeng, 2017), yang mendapatkan hasil berupa pengembangan perangkat pembelajaran berbasis Project-Based Learning terbukti berpengaruh terhadap kemampuan berpikir kritis siswa. Ketiga penelitian yang dilakukan oleh (Cahyaningsih et al., 2020), yang mendapatkan hasil berupa model Project Based Learning berbantu multimedia power point dinyatakan efektif untuk meningkatkan hasil belajar IPA.

Implikasi penelitian tindakan kelas (PTK) ini adalah dengan penerapan model pembelajaran PjBL akan membuat suasana pembelajaran yang aktif, kreatif, efektif dan menyenangkan, sehingga akan berdampak pada pembelajaran yang lebih bermakna bagi siswa.

\section{Simpulan}

Berdasarkan hasil analisis data dan pembahasan penelitian maka dapat disimpulkan bahwa penerapan pembelajaran berbasis Project Based Learning (PjBL) dapat meningkatkan aktivitas dan hasil belajar pada mata pelajaran laundry siswa kelas XII Perhotelan D SMKN 3 Denpasar Tahun Pelajaran 2020/2021. Implikasi penelitian ini adalah dengan penerapan model pembelajaran PjBL akan membuat suasana pembelajaran yang aktif, kreatif, efektif dan menyenangkan, sehingga akan berdampak pada pembelajaran yang lebih bermakna bagi siswa.

\section{Daftar Rujukan}

Afifah, A. N., Ilmiyati, N., \& Toto. (2019). Model project based learning (PjBL) terintegrasi stem untuk meningkatkan penguasaan konsep dan aktivitas belajar siswa. Quagga: Jurnal Pendidikan Dan Biologi, 11(2), 73-78. https://doi.org/10.25134/quagga.v11i2.1915

Amelia, D. J., \& Saputra, S. Y. (2017). Analisis Kelayakan Buku Siswa Kelas IV Tema Makhluk Hidup Kurikulum 2013. Pedagogia: Jurnal Pendidikan, 6(1), 98-109. https://doi.org/10.21070/pedagogia.v6i1.617 
Ardianingsih, F., Mahmudah, S., \& Rianto, E. (2017). Peran Guru Dalam Implementasi Kurikulum 2013 Pendidikan Khusus Pada Sekolah Luar Biasa Di Sidoarjo. Jurnal Pendidikan, 2(1), 14-20. https://doi.org/10.26740/jp.v2n1.p21-30

Cahyaningsih, R. N., Siswanto, J., \& Sukamto. (2020). Keefektifan Model Project Based Learning Berbantu Multimedia Power Point Terhadap Hasil Belajar IPA. Jurnal Penelitian Dan Pengembangan Pendidikan, 4(1), 34-40. https://doi.org/10.23887/jppp.v4i1.25014

Divayana, D. G. H., Suyasa, P. W. A., \& Sugihartini, N. (2016). Pengembangan media pembelajaran berbasis web untuk matakuliah kurikulum dan pengajaran di jurusan pendidikan teknik informatika Universitas Pendidikan Ganesha. Jurnal Nasional Pendidikan Teknik Informatika (Janapati), 5(3), 149. https://doi.org/10.23887/janapati.v5i3.9922

Faizah, U. (2015). Penerapan Pendekatan Saintifik Melalui Model Project Based Learning Untuk Meningkatkan Ketrampilan Proses Dan Hasil Belajar Siswa Kelas IV SD Negeri Seworan, Wonosegoro. Scholaria: Jurnal Pendidikan Dan Kebudayaan, 5(1), 24-38. https://doi.org/10.24246/j.scholaria.2015.v5.i1.p24-38

Faizin, N., Khairil, \& Sabr, M. (2017). Penggunaan Model Pembelajaran Project Based Learning Terhadap Peningkatan Hasil Belajar Kognitif Siswa Pada Materi Sistem Pernapasan Manusia Di MAN 1 Sigli Kabupaten Pidie. Jurnal Biotik, 5(1), 1-5. https://doi.org/10.22373/biotik.v5i1.2969

Hasanah, I., Sarwanto, S., \& Masykuri, M. (2018). Pengembangan Modul Suhu dan Kalor Berbasis Project Based Learning untuk Meningkatkan Keterampilan Proses Sains dan Kemampuan Berpikir Kritis Siswa SMA/MA. Jurnal Pendidikan (Teori Dan Praktik), 3(1), 38-44. https://doi.org/10.26740/jp.v3n1.p38-44

Krissandi, A. D. S., \& Rusmawan, R. (2015). Kendala Guru Sekolah Dasar Dalam Implementasi Kurikulum 2013. Jurnal Cakrawala Pendidikan, 3(3), 457-467. https: //doi.org/10.21831/cp.v3i3.7409

Kristiyanto, D. (2020). Peningkatan Kemampuan Berpikir Kritis dan Hasil Belajar Matematika dengan Model Project Based Learning (PJBL). Mimbar Ilmu, 25(1), 1-10. https://doi.org/10.23887/mi.v25i1.24468

Kurniaman, O., \& Noviana, E. (2017). Penerapan Kurikulum 2013 Dalam Meningkatkan Keterampilan, Sikap, Dan Pengetahuan. Primary: Jurnal Pendidikan Guru Sekolah Dasar, 6(2), 389. https://doi.org/10.33578/jpfkip.v6i2.4520

Kurniasari, F. (2017). Implementasi Pendekatan Saintifik Pada Penugasan Aktivitas Di Buku Teks Bahasa Indonesia Kelas VII SMP Berdasarkan Kurikulum 2013. Jurnal Pendidikan Edutama, 4(1), 9-26. https://doi.org/10.30734/jpe.v4i1.44

Kurniawan, D. T. (2017). Penggunaan Model PjBL Untuk Meningkatkan Kreativitas Mahasiswa Dalam Membuat Media Pembelajaran Matematika. Kalamatika: Jurnal Pendidikan Matematika, 2(2), 207. https://doi.org/10.22236/kalamatika.vol2no2.2017pp207-220

Kurniawan, H. R., Elmunsyah, H., \& Muladi, M. (2018). Perbandingan Penerapan Model Pembelajaran Project Based Learning (PJBL) dan Think Pair Share (TPS) Berbantuan Modul Ajar Terhadap Kemandirian dan Hasil Belajar Rancang Bangun Jaringan. JP (JURNAL PENDIDIKAN), 3(2), 80 - 85. https://doi.org/10.26740/jp.v3n2.p80-85

Mutakinati, L., \& Anwari, I. (2018). Jurnal Pendidikan IPA Indonesia Analysis Of Students ' Critical Thinking Skill of Middle School Through Stem Education Project-Based Learning. Jurnal Pendidikan IPA Indonesia, 7(1), 54-65. https://doi.org/10.15294/jpii.v7i1.10495

Nuryana, N., \& Sahrir, D. C. (2020). Pelatihan Kurikulum 2013 Edisi Revisi 2018 bagi Guru di Yayasan Pendidikan Islam Al-Maunah. Jurnal Pengabdian Pada Masyarakat, 5(1), 1 - 10. https://doi.org/10.30653/002.202051.259

Pratiwi, E. T., \& Setyaningtyas, E. W. (2020). Kemampuan Berpikir Kritis Siswa SD dengan Model Pembelajaran Problem Based Learning dan Model Pembelajaran Project Based Learning. Jurnal Basicedu, 4(2), 379-388. https://doi.org/10.31004/basicedu.v4i4.445

Purwaningsih, E., Sari, S. P., Sari, A. M., \& Suryadi, A. (2020). The Effect Of Stem-PjBL And Discovery Learning On Improving Students ' Problem-Solving Skills Of The Impulse And Momentum Topic. Jurnal Pendidikan IPA Indonesia, 9(4), 465-476. https://doi.org/10.15294/jpii.v9i4.26432 
Raditya, A., \& Iskandar, R. S. F. (2020). Analisis Soal PLSV pada Buku Ajar Matematika dari Kurikulum 1994 hingga Kurikulum 2013. Phenomenon: Jurnal Pendidikan MIPA, 9(2), 232-145. https://doi.org/10.21580/phen.2019.9.2.4066

Sumarni, W., Wardani, S., \& Gupitasari, D. N. (2016). Project Based Learning (PBL) To Improve Psychomotoric Skills : A Classroom Action Research. Jurnal Pendidikan IPA Indonesia, 5(2), 157163. https://doi.org/10.15294/jpii.v5i2.4402

Tesi Muskania, R., \& Wilujeng, I. (2017). Pengembangan Perangkat Pembelajaran Project-Based Learning Untuk Membekali Foundational Knowledge Dan Meningkatkan Scientific Literacy. Jurnal Cakrawala Pendidikan, 36(1), 34-43. https://doi.org/10.21831/cp.v36i1.8830

Trimawati, K., Kirana, T., \& Raharjo, R. (2020). Pengembangan Instrumen Penilaian IPA Terpadu Dalam Pembelajaran Model Project Based Learning (PjBL) Untuk Meningkatkan Kemampuan Berpikir Kritis Dan Kreatif Siswa SMP. Quantum: Jurnal Inovasi Pendidikan Sains, 11(1), 36. https://doi.org/10.20527/quantum.v11i1.7606 